\title{
POLÍTICAS PÚBLICAS DE FOMENTO À ECONOMIA CRIATIVA: CURITIBA E CONTEXTO NACIONAL E INTERNACIONAL
}

\author{
PUBLIC POLICIES OF PROMOTION TO CREATIVE ECONOMY: \\ CURITIBA AND NATIONAL AND INTERNATIONAL CONTEXT
}

\begin{abstract}
Mario Procopiuck ${ }^{1}$
Schirlei Mari Freder ${ }^{2}$

\section{RESUMO}

O tema "economia criativa" tem ocupado a pauta de diversos governos e de organizações internacionais de forma mais intensa nestes últimos cinco anos. Em estágio pré-paradigmático, são ainda relativamente poucos os pontos de consenso para que possam ser definidas claramente correntes teóricas. Não obstante, estudos se intensificam com vistas a buscar meios operacionais para que a base conceitual existente passe a pautar políticas públicas de desenvolvimento em diferentes contextos locais, nacionais e internacionais. Nesse sentido, modelos sobre economia criativa, classes criativas e cidades criativas têm sido propostos, e vários deles já começam dar origem a resultados empíricos. Nesse sentido, o presente artigo tem como objetivo trazer à reflexão diferentes perspectivas sobre economia criativa, tanto de cunho teórico quanto prático, apresentando o quadro geral das discussões sobre o tema em escala global para, em seguida, analisar estudos que procuram situar o patamar em que se desenvolve em Curitiba a política pública de fomento à economia criativa.
\end{abstract}

Palavras-chave: Economia criativa; Classes criativas; Indústrias criativas; Cidades criativas; Políticas públicas.

\begin{abstract}
The theme creative economics have been occupying an agenda of several governments and international organizations, more intensely in the last five years. In pre-paradigmatic stage, still are relatively few the consensus points to define clearly theoretical chains. Despite this, studies intensify the pursuit to find operational ways for the existent conceptual basis guide development public policies in different local contexts, national and international. Accordingly, models about creative economics, creative classes and creative cities have been proposed and several of them are already starting to have empirical results. This article, accordingly, have as goal bring the reflection of different perspectives about creative economy, much of theoretical nature as practical, presenting the general board of discussions about the theme in global scale, for, then, analyze studies that aims situate the level that is developed the public policies of promotion to creative economics in Curitiba.
\end{abstract}

Keywords: Creative economy; Creative classes; Creative industries; Creative cities; Public policies

\footnotetext{
${ }^{1}$ Doutor em Administração, Mestre em Gestão Urbana e Professor do Programa de Pós-graduação em Gestão Urbana da Pontifícia Universidade Católica do Paraná (PUCPR).

${ }^{2}$ Mestranda no Programa de Pós-graduação em Gestão Urbana da Pontifícia Universidade Católica do Paraná (PUCPR), Administradora e Especialista em Gestão Social e Desenvolvimento Sustentável.
} 


\section{Introdução}

Grande parte das aglomerações urbanas brasileiras, assim como ocorre em outros países, passa por um ritmo de desenvolvimento aquém do mínimo necessário para se manter atrativa em termos de vantagens comparativas. Os modelos clássicos adotados de organização espacial e de atividades econômicas revelam-se crescentemente incapazes de satisfazer às necessidades dos principais agentes econômicos e de cidadãos-residentes em cidades litorâneas com baixa concentração urbana e afastadas de grandes centros, caracterizadas por centralidade, históricos, etc.

A consequência disso é a falta de vantagens comparativas para desenvolvimento sustentável, em função da homogeneidade de recursos e competências disponíveis localmente e com baixa capacidade de gerar valor. Por um lado, há diminuição do nível de conforto, qualidade de vida e de bem-estar e, por outro, são abertos espaços para a marginalização social, insegurança, migração para grandes centros urbanos, etc. A perda da capacidade de se manter ativamente concatenados com novas exigências da evolução do capitalismo moderno tende a transformar esses contextos urbanos em espaços pouco promissores para desenvolvimento futuro.

Como meio de as cidades e regiões se manterem ativas e sustentáveis em termos econômicos, sociais e ambientais, grande parte do discurso capitalista contemporâneo tem defendido a necessidade de impulsionar o desenvolvimento criativo de tecnologias básicas, de sistemas de trabalho flexíveis e de estruturas de mercado, com fundamentos em dimensões cognitivo-culturais. Um dos meios vislumbrados por gestores urbanos, lideranças locais e acadêmicos para as cidades se posicionarem com vantagens nesse contexto de desenvolvimento socioeconômico tem passado normalmente por encontrar estratégias para atrair, realocar e aplicar produtivamente o capital intelectual em diferentes perfis de cidades.

Nessa linha, há cidades que, dentre uma infinidade de outras alternativas, investem no desenvolvimento de tecnologias avançadas, outras se especializam em configurar serviços inovadores, outras procuram incentivar atividades manufatureiras neoartesanais (moda, turismo, gastronomia, produtos audiovisuais, produtos culturais, etc.) e, ainda, há aquelas que procuram potencializar o desenvolvimento de produtos culturais. Isso tem levado à crescente necessidade de compreender a interface entre criatividade, cultura, economia e tecnologia para concepção, articulação e implementação de estratégias de desenvolvimento local sustentável.

Como alternativa promissora para enfrentar tais problemas, o conceito de economia criativa ganha relevância tanto em países em estágio de desenvolvimento avançado quanto naqueles em vias de desenvolvimento. Essa nova perspectiva se desvincula dos modelos econômicos tradicionais para assumir feições multidisciplinares para abarcar a economia, a tecnologia e a cultura, tendo como foco de atenção serviços e produtos culturais com elevados conteúdos criativos. Nessa linha, o presente artigo tem por objetivo explorar alternativas que possibilitem a criação de bases operacionais e, com fundamentos no conceito de cidades criativas, permitir maior clareza a gestores públicos, lideranças e sociedades locais para identificar potencialidades que viabilizem a inserção de cidades e localidades em trajetórias de desenvolvimento com base na economia criativa.

\section{Bases da Economia Criativa}

A teoria econômica clássica passou por alto relativamente às atividades culturais como potenciais de geração de desenvolvimento, haja vista que, como defendido por Adam Smith, 
as profissões dedicadas à arte, à cultura e ao entretenimento não contribuiriam para a geração de riquezas; logo, eram vistas como atividades não produtivas porque não gerariam valor agregado, por se constituírem em serviços finais que, pela sua natureza intangível, se esvaíam no momento de sua produção e consumo (CIEDES, 2010, p. 10). Entretanto, na proporção em que a teoria econômica se desenvolveu, suas perspectivas clássicas perderam capacidade explicativa a partir do paradigma industrial, e seus pressupostos normativos nucleares se tornaram insuficientes para promover o desenvolvimento de nações, portanto as ideias iniciais sobre serviços culturais foram sendo alteradas ao longo do tempo. Nesse processo, a criatividade cognitivo-cultural passou a constituir capital intelectual, que, por sua vez, adquiriu alta taxa de conversão em capital físico ou financeiro, abrindo espaços para a chamada economia criativa.

Como campo de conhecimento em estágio pré-paradigmático no processo de constituição, a definição de economia criativa ainda não possui contornos precisamente definidos quanto à abrangência, mesmo em discussões teóricas mais abstratas. A United Nations Conference on Trade and Development, com escopo bastante aberto ainda, considera a economia criativa "um conceito emergente para lidar com a interface entre criatividade, cultura, economia e tecnologia em um mundo contemporâneo dominado por imagens, sons, textos e símbolos" (UNCTAD, 2013).

Não obstante a falta de bases teóricas mais consistentes, já tem sido possível a adoção de estratégias que permitam a modelagem de políticas públicas com a finalidade de formar férteis contextos locais para conceber e implementar ações público-privadas para despertar capacidades cognitivo-culturais e contribuir para a alavancagem de atividades industriais e manufatureiras tradicionais, com vistas a elevar possibilidades de tornar comunidades urbanas viáveis não só economicamente, mas, ao mesmo tempo, coesas internamente pelo fortalecimento de laços de sociabilidade, de solidariedade e de participação democrática (SCOTT, 2007). Nesse sentido é que se justifica a importância de se compreender a interface entre criatividade, cultura, economia e tecnologia para concepção, articulação e implementação de estratégias de desenvolvimento local sustentável, aliando a dimensão econômico-criativa à ideia de cidades criativas.

A economia criativa vem sendo utilizada pelos países desenvolvidos para revitalizar o crescimento socioeconômico e fomentar a inovação, sobressaindo-se como estratégia importante para a redução do desemprego e para a melhoria dos níveis de competitividade de países, regiões e localidades. A economia criativa tem como vantagem permitir que cada país, região ou localidade explore habilidades, conhecimentos tradicionais e heranças culturais para fomentar o setor criativo e, ao mesmo tempo, promover a identidade cultural e auxiliar na inserção de atividades criativas nos setores de maior crescimento da sociedade contemporânea (UNCTAD, 2011).

Nessa linha, a Comissão Europeia, por exemplo, tem envidado esforços desde 2007 para a implementação da "Agenda Europeia da Cultura", com fins de encorajar autoridades nacionais e arranjos institucionais governados pela própria Comissão para promoção conjunta da diversidade e do diálogo cultural, da cultura como catalisadora da criatividade e da inovação, colocando a cultura como parte das relações internacionais da União Europeia. Como medidas práticas estão sendo criadas estruturas de suporte, como: (a) grupo de peritos dos Estados-Membro, formado em 2008, que visa utilizar estratégias de programas de apoio da União Europeia a fundos estruturais, estratégias de exportação e internacionalização, e boas práticas em engenharia financeira para pequenas e médias empresas do setor cultural e criativo; e (b) Plataforma da Sociedade Civil, criada em 2008, cuja contribuição se traduziu 
em recomendações em 2010 sobre políticas e, na atualidade, trabalha com temáticas relacionadas a finanças e tributação, coesão regional, ambiente digital, mobilidade, e educação e competências. Em 2014 entra em atividade o Programa "Europa Criativa", com a finalidade de fortalecer o potencial competitivo dos setores culturais e criativos em direção à "economia inteligente, sustentável e inclusiva" defendida pela estratégia "Europa 2020" (SANTOS, 2012, p. 17).

A economia criativa, assim, se mostra com potencialidade de gerar crescimento econômico e desenvolvimento, com potencial de gerar renda, emprego e promover inclusão social e desenvolvimento humano a partir da interação criativa de recursos econômicos, culturais e sociais com recursos tecnológicos para gerar utilidades de natureza cognitivoculturais. Surge como área de conhecimento e como campo de atuação prática que abrange desde níveis macro até níveis micro, requerendo abordagens multidisciplinares e políticas inovadoras para impulsionar indústrias, cidades e nações criativas.

\section{Políticas públicas de desenvolvimento no contexto da Economia Criativa}

No campo de práticas, principalmente na formulação e implementação de políticas públicas, ainda não há referencial único a ser utilizado com capacidade de obtenção de convergência entre políticos, gestores, lideranças da sociedade civil organizada e empreendedores culturais. Situação similar ocorre também no contexto de estudos acadêmicos. Embora significativos avanços já tenham ocorrido, grandes desafios para desenvolvimento de modelos operacionais se encontram na determinação de fronteiras entre arte, cultura e indústria, na inserção de tecnologias e na colocação de produtos em contextos de negócios (UNCTAD, 2010).

Não obstante as dificuldades ainda existentes para se agir sistemática e intencionalmente no fomento da economia criativa, a realidade mostra que em centros urbanos normalmente há uma ampla gama de agentes culturais que atua em diferentes fases de cadeias de indústrias criativas, desde o ato criativo até a produção e distribuição de bens e serviços. Com suporte na economia criativa, nesses centros é possível identificar relações público-privadas com a finalidade de potencializar a criatividade e o empreendedorismo para dinamizar bases de desenvolivimento sustentável. As cidades, principalmente por relações de proximidade entre agentes produtivos, se constituem em terreno fértil para a formação de arranjos criativos com potenciais de geração de impactos globais. Em particular, as cidades criativas podem ser desde aquelas pequenas o suficiente para afetar apenas indústrias culturais locais até as suficientemente grandes para servirem de portais para os mercados internacionais (UNESCO, 2013).

Nessa perspectiva, mudando o foco da discussão de perspectivas gerais sobre economia criativa, indústrias criativas e cidades criativas para pessoas, os ambientes urbanos podem ser vistos como habitats criativos que se formam a partir de políticas de desenvolvimento local, que procuram torná-los atrativos para profissionais altamente qualificados tecnológica e culturalmente (SELADA; CUNHA 2012). Nesse processo, nações se transformam e continuam a se transformar estruturalmente, a exemplo do que vem ocorrendo desde longa data com o perfil da mão de obra dos Estados Unidos, conforme indicado no Gráfico 1. 


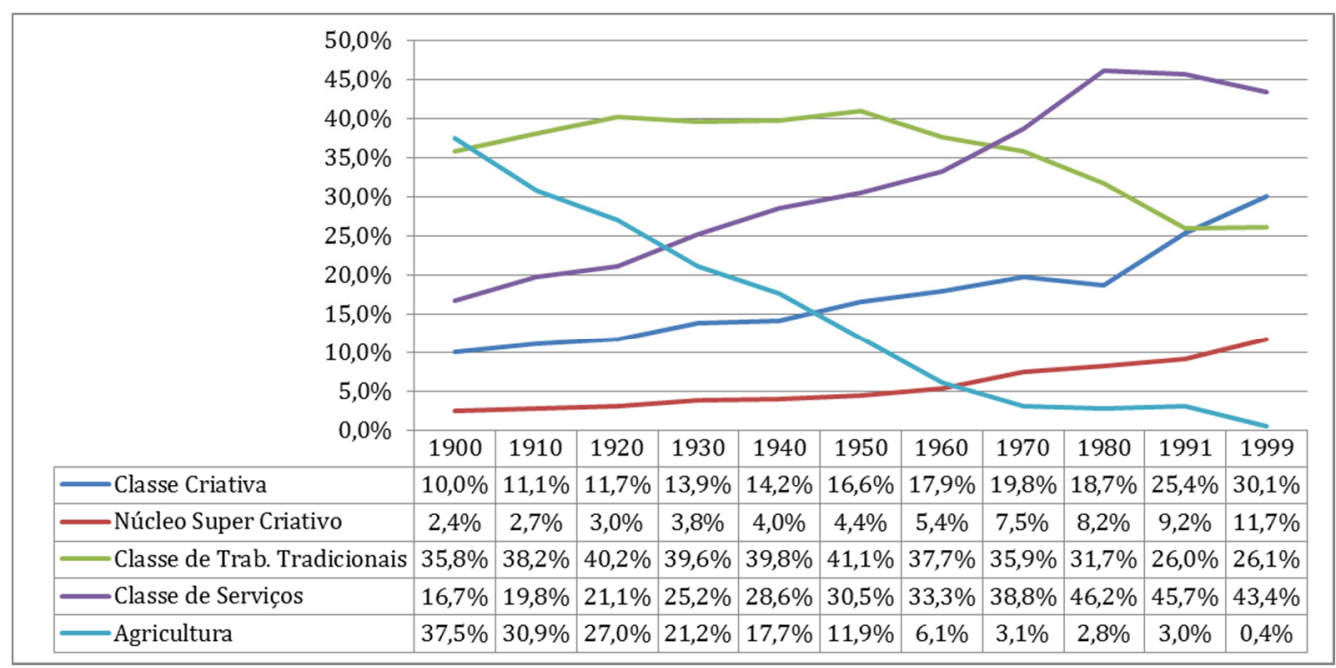

Gráfico 1 - Participação histórica de classes de trabalhadores nos EUA (1900-1999) Fonte: Florida (2002).

De modo geral, uma das primeiras evidências sobre a importância da economia criativa, formada por agentes e estruturas de serviços para geração de utilidades e bens criativos, pode ser obtida com base no comércio internacional, conforme dados que deram origem à Figura 1. Nesse mapa, estão indicados os somatórios de resultados financeiros de exportações de bens e serviços criativos na década compreendida entre 1999 e 2008.

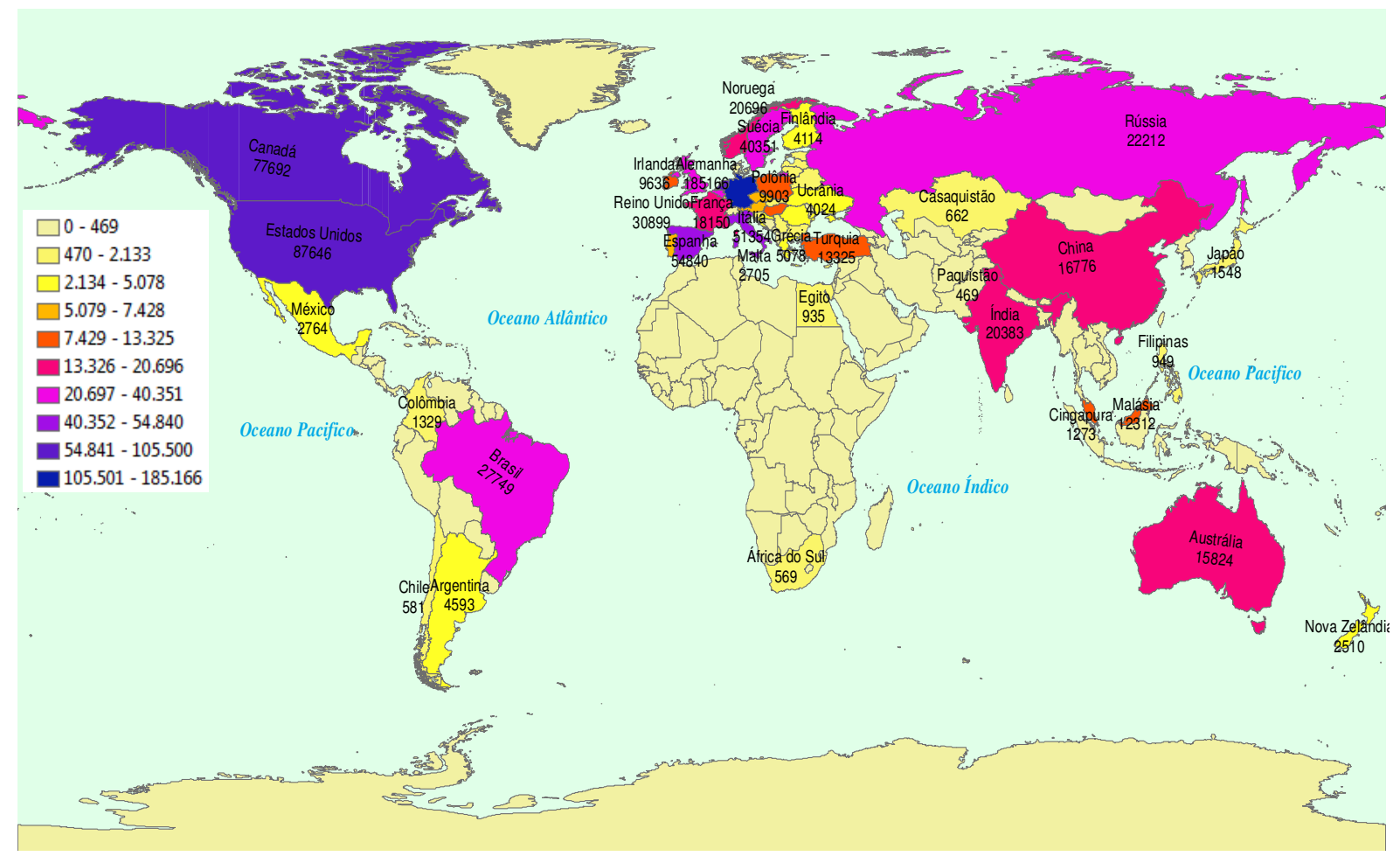

Figura 1 - Mapa das exportações de bens e serviços da economia criativa entre 1999 e 2008, em milhões de dólares

Fonte: Mapa, elaborado pelos autores a partir de dados UNCTAD (2008, p. 295-296; 2010, p. 319-320)

RBPD - Revista Brasileira de Planejamento e Desenvolvimento, v. 2, n. 2, p. 15-29, jul./dez. 2013. 
Além da visão geral da distribuição geográfica do comércio mundial de bens e serviços criativos, trazida pela Figura 1, em termos de resultados econômicos globais, o Relatório da United Nations Conference on Trade and Development (UNCTAD, 2008) trás outros indicadores sobre a importância das indústrias criativas, indicando o quão dinâmica tem se tornado no mundo dos negócios. Por exemplo, as exportações mundiais de produtos criativos passaram de \$227,5 bilhões em 1996 para \$ 424,4 bilhões em 2005. O Relatório da UNCTAD (UNCTAD, 2010) registra que, entre 2002 e 2008, bens e serviços criativos, apesar da crise econômica que afetou grande parte dos países desenvolvidos, tiveram crescimento anual médio de $14 \%$. O comércio mundial de bens e serviços criativos alcançou $\$ 592$ bilhões em 2008.

No caso brasileiro, há estimativas de que cadeias produtivas da indústria criativa contribuíram com 16,4\% do Produto Interno Bruto (PIB), o que corresponde a R\$381,3 bilhões. As contribuições principais para originar esses números vêm da indústria da moda e da arquitetura. Especificamente no estado do Rio de Janeiro, a cadeia da indústria criativa participa com 17,8\% do PIB estadual, ou seja, com aproximadamente R\$ 54,6 bilhões (FIRJAN, 2008, p. 3-4).

Nacionalmente, com fundamentos na economia criativa, no Brasil há esforços sendo desenvolvidos desde 2003 (MIGUEZ, 2007). Entretanto, como política pública, somente ganhou força e passou a ser desenvolvida e articulada com maior intensidade a partir de 2011, quando o Ministério da Cultura criou a Secretaria de Economia Criativa - SEC (BRASIL, 2011).

A SEC, desde então, vem realizando reuniões de pactuação e alinhamento de ações com os ministérios do governo federal, com instituições financeiras e de fomento. Ações também passaram a ser difundidas para estados e municípios. Por ser um tema transdisciplinar que envolve vários segmentos e setores da economia, os trabalhos interministeriais e os desdobramentos realizados pelas secretarias estaduais e municipais específicas representam o maior desafio na consolidação dessa proposta (LEITÃO, 2011).

\section{Indústria criativa e setores criativos no contexto das cidades criativas}

A expressão inglesa creative industries normalmente é traduzida como "indústrias criativas". Entretanto, o Ministério da Cultura, responsável pela política pública de fomento à economia criativa brasileira, julgou ser necessário alterar a nomenclatura para setores criativos. São apresentados como argumentos para a alteração o fato de, em inglês, o termo "industry" apresentar correspondência mais próxima com o que se compreende como "setor" em português, ou seja, a um conjunto de organizações ou empresas que realizam uma atividade em comum. Em virtude disso, optou-se pela expressão "setores criativos como representativo dos diversos conjuntos de empreendimentos que atuam no campo da Economia Criativa" (BRASIL, 2011, p. 22).

O mesmo problema sobre a acepção do termo "indústria" surgido no Brasil ocorreu também, por exemplo, na Rússia, em cuja língua o significado do termo é parecido com o interpretado pelo Ministério da Cultura do Brasil. A necessidade de reconceituação naquele país teve como reflexo o surgimento de dificuldades para a geração de estatísticas comparáveis internacionalmente (RUUTU; PANFILO; KARHUNEN, 2009, p. 14-15). Tanto em um caso quanto no outro, buscar bases comparativas exigirá esforços no sentido de desenvolver arcabouços teóricos conceituais capazes de explicitar diferenciações sem, entretanto, descartar possibilidades de manter bases comparativas, mesmo que parciais. No 
caso brasileiro, tal preocupação parece ainda não estar muito clara, pelo menos na política do Ministério da Cultura.

Globalmente, as indústrias criativas começaram a ganhar forma a partir da definição de diretrizes claras pelo governo australiano para a política cultural, no início dos anos 1990. O objetivo à época era aliar criativamente cultura e tecnologia para alçar o país em posição competitiva no novo mercado de novas tecnologias de informação e comunicação, que então emergia (AUSTRALIA, 1994). Apesar de as origens das indústrias criativas estarem vinculadas à indústria cultural e muitos países as tratarem alternadamente, o conceito de indústria criativa, mesmo apresentando estreitas relações, atualmente é diferente das tradicionais noções sobre funcionamento do setor cultural. As indústrias criativas, com dinâmica e lógica de funcionamento próprias, são mais que simples derivações de setores culturais, como concebido, por exemplo, pelo Ministério da Cultura brasileiro.

As indústrias criativas abrangem processo de criação, produção, comercialização e distribuição de bens e serviços, frutos da criatividade humana e da aplicação de capital intelectual, e têm por finalidade criar valor econômico e cultural, conteúdo criativo e realizar objetivos de mercado. São indústrias que fazem interface entre atividades econômicas com base no conhecimento e, caracteristicamente, trabalham com bens tangíveis e realização de serviços intelectuais intangíveis (UNCTAD, 2011). Uma visão completa das indústrias criativas pode ser obtida analisando a Figura 1.

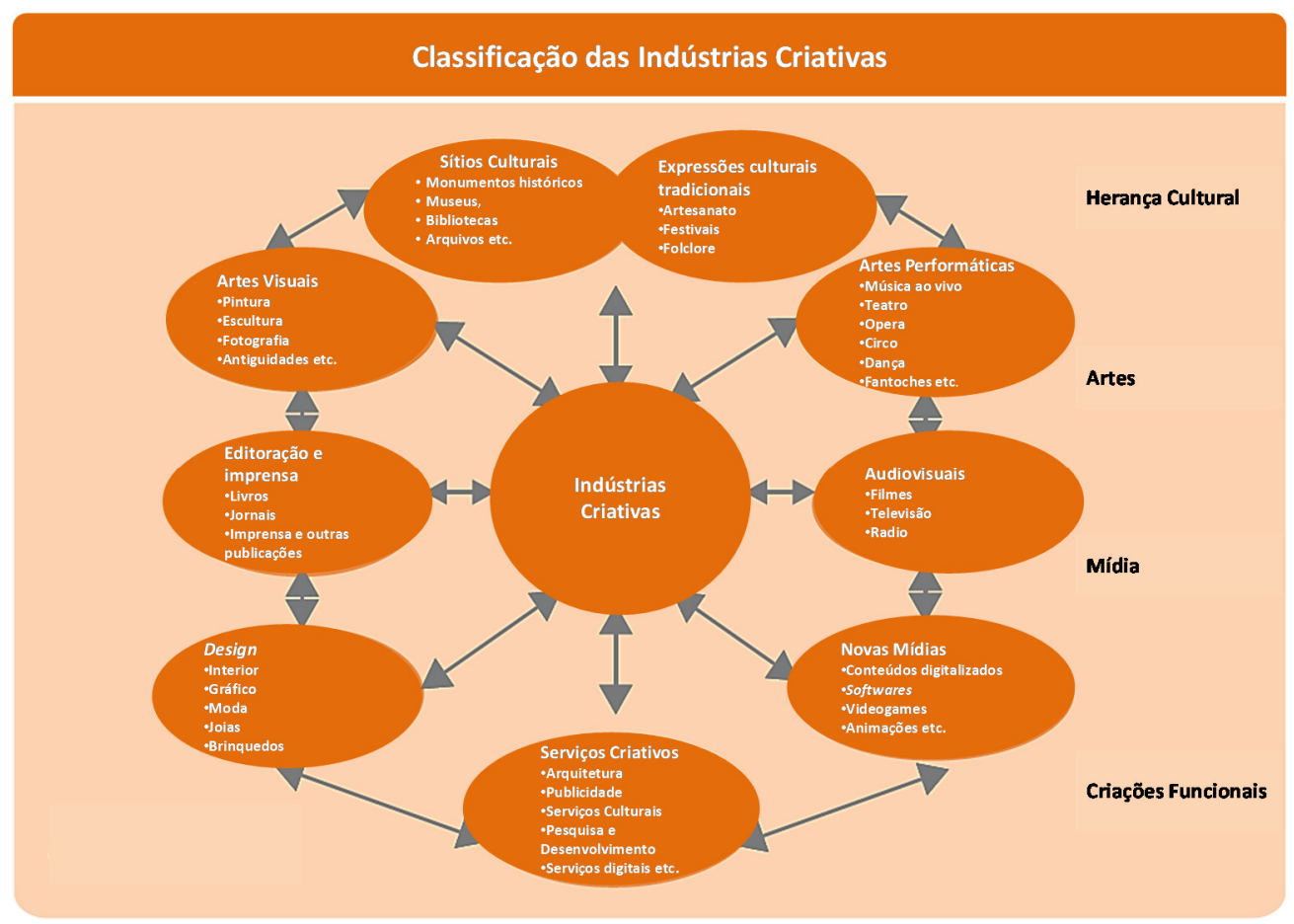

Figura 2 - Classificação das indústrias criativas

Fonte: Unctad (2010; 2013, p. 8), tradução livre.

No contexto de atuação governamental para fomento da economia criativa em contextos nacionais, além das clássicas atividades econômicas - alocação eficiente de recursos na economia, busca do pleno emprego, estabilidade de preços, equilíbrio na balança comercial, distribuição equânime de renda e de bem-estar, etc. -, é requerida uma série de novas capacidades e habilidades específicas passíveis de ser criadas em diferentes contextos, 
conforme recursos e competências culturais e criativas disponíveis localmente.

\section{a. Experiências internacionais sobre indústrias criativas}

A literatura tem indicado o Reino Unido, a Austrália, a Nova Zelândia e o Canadá como referências em termos de desenvolvimento teórico-conceitual sobre indústrias criativas, bem como fortes impulsionadores de políticas públicas de estímulo às indústrias criativas. Menções sobre grandes investimentos e esforços para desenvolver indústrias criativas são feitas relativamente a políticas públicas desenvolvidas nos Estados Unidos, China, Índia, Japão, Coreia e Austrália (NEWBIGIN, 2010; BOTELHO, 2011; COSTA; SOUZA-SANTOS, 2012).

A Austrália, que merece destaque pela relativamente longa trajetória em busca de definições operacionais para se posicionar estrategicamente na economia criativa, revisou em 2011 a sua classificação de indústrias criativas considerando perspectivas futuras. As novas bases classificatórias constam do Creative Industries, a Strategy for 21st Century Australia, do Department of Regional Australia, Local Government, Arts and Sport. As indústrias culturais são reforçadas sob o argumento de que artes e cultura enriquecem a sociedade, refletem identidade nacional e estão no núcleo do nascente setor de indústrias australianas (AUSTRALIA, 2011). Nessa indústria, para formulação de políticas públicas, a criatividade é vista como chave para a inovação, como diretriz para o crescimento, sustentabilidade e prosperidade. A inovação criativa, como capital cultural, é buscada nas artes, ciências, negócios, pesquisa e desenvolvimento, e nas comunidades (AUSTRALIA, 2011).

Como integrantes da indústria criativa australiana, foram considerados seis grandes grupos formados por música e artes performáticas; filmes, televisão e rádio; publicidade e marketing; desenvolvimento de software e conteúdo interativo; produção literária, editoração e meios de comunicação impressos; arquitetura, desenho e artes visuais. Em relação à composição da indústria criativa, embora reconhecendo explicitamente a inexistência de acordos universais, foi utilizada a definição desenvolvida pelo Creative Industries and Innovation (CCI), da Queensland University of Technology (AUSTRALIA, 2011).

A indústria criativa australiana é formada principalmente por pequenas empresas localizadas em âmbito metropolitano, regional e rural, e tem na política pública do governo nacional o incentivo para inserção em ambiente competitivo global, o que é feito por alavancagem por fundações nacionais (fomento à inovação, exploração de infraestrutura, investimento em capital humano, aproveitamento de pesquisas), otimização da capacidade comercial (aperfeiçoamento de empreendimentos, obtenção de negócios e investimentos, identificação de mercados consumidores), fomento de conteúdo criativo e de serviços (definir diretrizes para inovação criativa, promover direitos de propriedade intelectual, explorar modelos flexíveis de negócios, defender redes e espaços colaborativos) (AUSTRALIA, 2011).

Em termos de resultados econômicos, a indústria criativa da Austrália contribuiu com \$31,1 bilhões no período 2008-2009, com crescimento real na ordem de 3,9\%, que se mantém superior em relação ao desempenho global da economia nos últimos dez anos. A indústria criativa, conforme estimativas baseadas no senso de 2006, ocupava 438 mil pessoas, o que corresponde a 4,8\% da mão de obra empregada. De modo geral, o desenvolvimento de software e de conteúdo interativo está em posição dominante, com $43 \%$ da receita industrial, e ocupa 39\% da mão de obra do setor. O Gráfico 2 traz a configuração da proporção de empregos gerados em diferentes setores da economia criativa. 


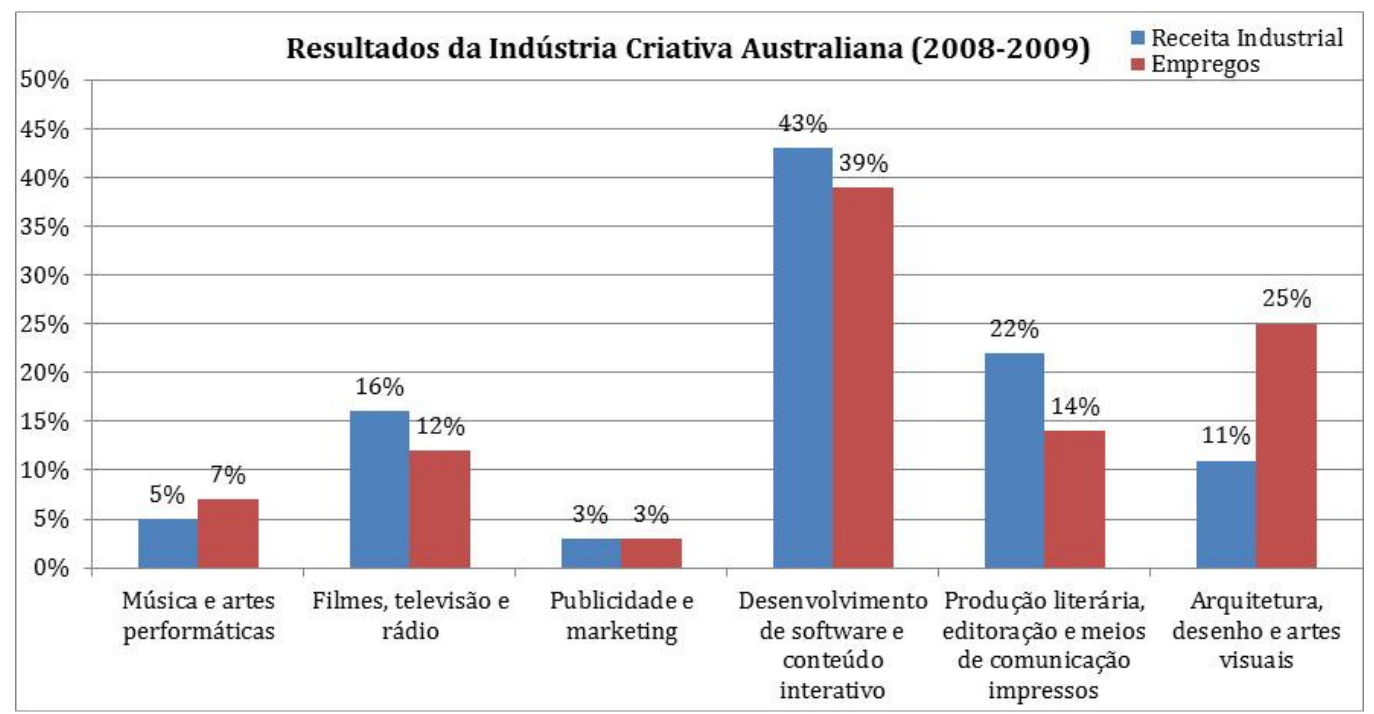

Gráfico 2 - Resultados da Indústria Criativa Australiana (2008-2009)

Fonte: Australia (2011, p. 6).

Embora represente apenas um exemplo pontual sobre a importância das indústrias criativas, o exemplo australiano se constitui em importante referencial para a estruturação de políticas públicas abrangentes e em perspectivas de longo prazo.

\section{b. Mapeamento das discussões globais sobre indústrias criativas}

De modo mais amplo, agora procurando indícios de seu grau atual de reverberação a partir da sociedade global, a importância assumida pela temática indústria criativa pode ser aferida objetivamente a partir de levantamentos na internet, obtendo referenciais como o mapa a seguir (Figura 3). Esse mapa foi elaborado a partir de dados levantados na internet, utilizando domínios de topo (country-code top-level domains ou ccTLD) de cada país. Esses domínios, atualmente em número de 250, são definidos pelo código ISO 3166-1 alpha-2, publicado e atualizado pela International Organization for Standardization. Aplicado para organização da internet, o domínio de topo é a sigla que serve para localizar e identificar conjuntos de computadores localizados em cada país e em suas dependências. Esses códigos, quando utilizados de acordo com regras de programas de busca, como o Google, possibilitam isolar o número de ocorrências em consultas por país, de acordo com parâmetros formados por palavras, termos, frases, etc. Tendo como elemento de pesquisa a expressão "creative economy", a pesquisa exploratória foi realizada em janeiro de 2013, quando foram identificados 1.001.451 documentos eletrônicos. A distribuição quantitativa desses por país está representada na Figura 3. 


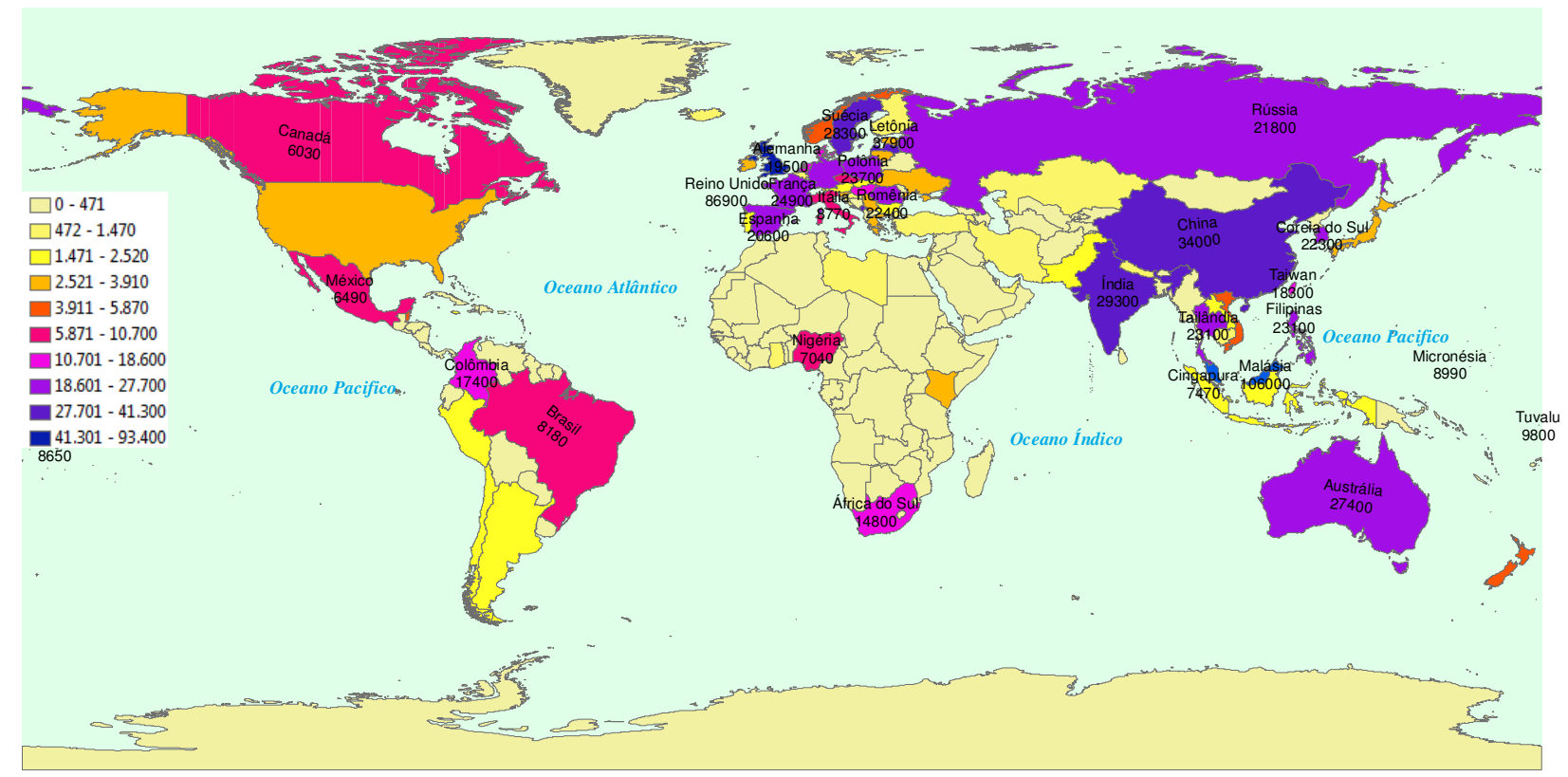

Figura 3 - Discussão mundial na internet sobre indústrias criativas

Fonte: Elaborado pelos autores.

No mapa, em ordem decrescente de frequência, aparecem entre os primeiros Suíça (139.000), Malásia (106.000), Reino Unido (86.900), Letônia (37.900), China (34.000), Montenegro (30.200), Índia (29.300), Suécia (28.300) e Austrália (27.400). Nessa lista, o Brasil ocupa a $30^{\mathrm{a}}$ posição e está situado no $6^{\circ}$ grupo representado na legenda retangular. Esse posicionamento está em consonância com a $7^{a}$ colocação no volume de exportações de bens e serviços com origem na economia criativa, conforme explicitado na Figura 1.

\section{c. Posicionamento da classe criativa de Curitiba frente a outras capitais brasileiras}

Apesar de existir no Paraná, e especialmente em Curitiba, uma série de iniciativas e movimentos relacionados à economia criativa, ainda são raros os estudos que procuram demonstrar dados objetivos que permitam comparar a realidade local e regional com a de outras cidades brasileiras. Um dos poucos trabalhos sobre cidades criativas foi desenvolvido por Machado (2012), apesar de representar apenas a dimensão econômica e abordar mais o que na teoria é considerado como parte da classe criativa (PECK, 2005; ATKINSON; EASTHOPE, 2009; HOYMAN; FARIC, 2009).

Mesmo com escopo limitado em relação ao conceito de economia criativa, o trabalho de Machado (2012) permite levantar pontos importantes para discussões sobre o posicionamento de Curitiba no contexto das grandes cidades brasileiras, principalmente quando considerada em perspectiva histórica a alocação de força de trabalho em setores criativos. $\mathrm{O}$ estudo abrangeu os 10 maiores centros urbanos brasileiros. A conclusão foi de que apenas 2,27\% da População Economicamente Ativa (PEA) desses centros urbanos estão alocados em atividades criativas. Nesse grupo de cidades, São Paulo se destaca com 2,84\% de ocupação da PEA em atividades criativas (MACHADO, 2012). Sobre São Paulo, esse percentual se aproxima bastante dos $3 \%$ estimados por Caiado (2011, p. 9). 
Em Curitiba, como pode ser verificado no Gráfico 3, abaixo, a taxa de ocupação era de apenas $1,96 \%$ em 2008, o que a situou na penúltima posição entre as cidades objeto do estudo - tomando como referencial de comparação internacional desses percentuais, por exemplo, o número de pessoas empregadas na indústria criativa da Austrália, que, em 2008, foi de 4,8\% (AUSTRALIA, 2011).

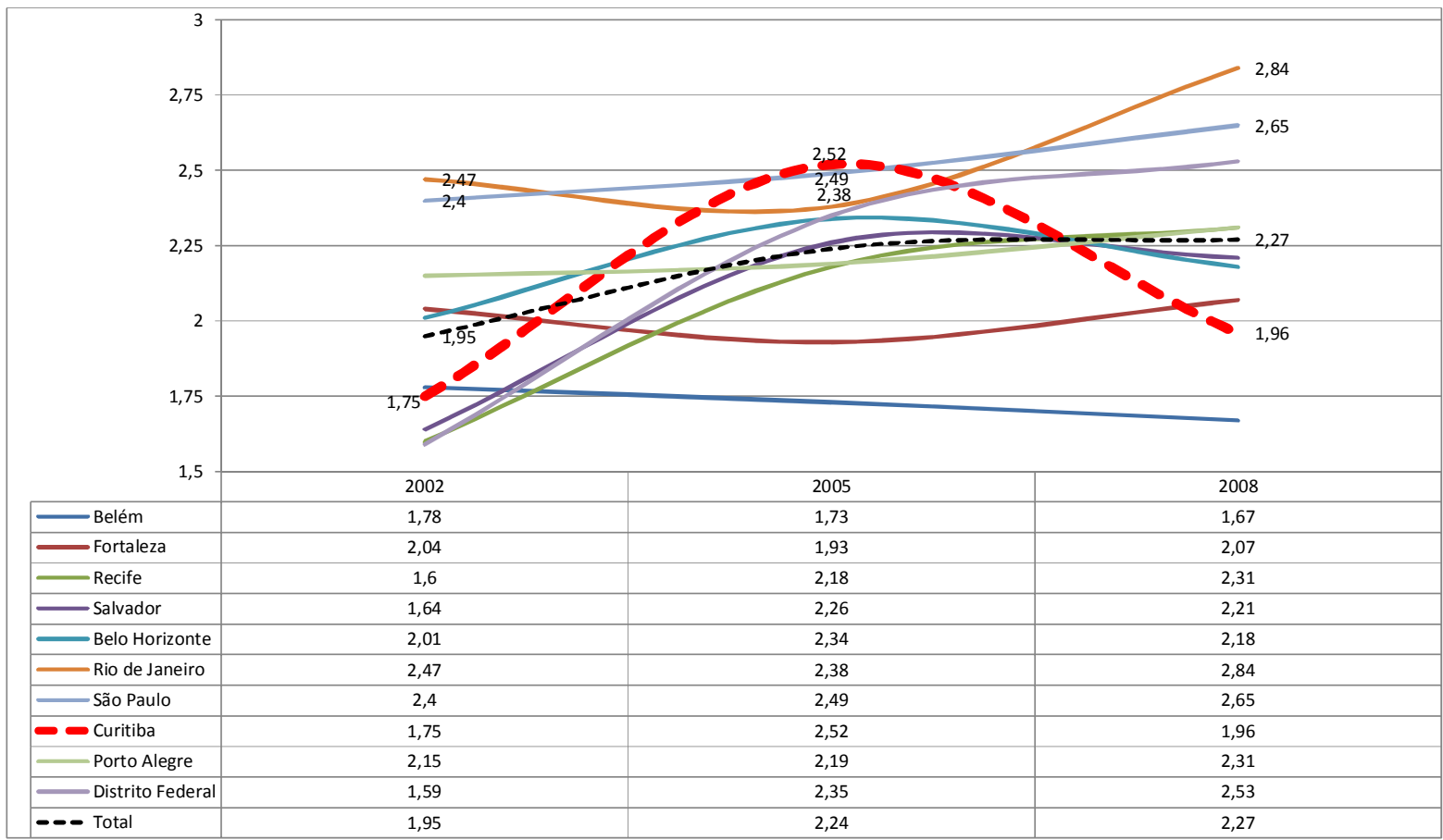

Gráfico 3 - População Economicamente Ativa alocada em atividades criativas

Fonte: Machado (2012).

No caso de Curitiba, o que chama atenção no é o índice abaixo da média geral em 2002, a elevação para patamar superior em 2005 e, em 2008, a queda brusca para nível bastante parecido em relação à média de 2002. Merece destaque também que, apesar de todas as três apresentarem crescimento relativamente a 2002, a trajetória de Curitiba tomou direção descendente e oposta, por exemplo, relativamente às de São Paulo e Rio de Janeiro, em 2005 e 2008. A abrupta variação dos dados para Curitiba relativamente à ocupação da PEA em atividades criativas certamente terá de ser avaliada sob outras perspectivas para se buscar maior clareza quanto às causas.

\section{d. Cenário brasileiro de cidades criativas e cidades paranaenses}

No estudo de Machado (2012), considerando condições funcionais e infra-estruturais locais expressas na Tabela 1, também categorizou, por meio de método de seleção a partir de posicionamentos extremos, os municípios brasileiros em não criativos, pouco criativos, algo criativos e criativos, de acordo com cinco grandes regiões geográficas. Na categorização, além dos quatro extremos distintivos demonstrados no gráfico, há a categoria "misto", não definida quantitativamente. 
Tabela 1 - Condições funcionais e infra-estruturais para classificação de municípios criativos

\begin{tabular}{|c|c|c|}
\hline $\begin{array}{l}\text { 1) Existência de órgão gestor da } \\
\text { cultura; } \\
\text { 2) Existência de página na } \\
\text { Internet do órgão gestor da } \\
\text { cultura; } \\
\text { 3) Total do pessoal ocupado no } \\
\text { órgão gestor da cultura } \\
\text { ponderado pela população } \\
\text { estimada em 2006; } \\
\text { 4) Existência de política } \\
\text { municipal de cultura; } \\
\text { 5) Adesão do município ao } \\
\text { Sistema Nacional de Cultura; } \\
\text { 6) Presença de consórcio } \\
\text { intermunicipal de cultura; }\end{array}$ & $\begin{array}{l}\text { 7) Existência de legislação municipal } \\
\text { de fomento à cultura; } \\
\text { 8) Existência de Conselho Municipal } \\
\text { de Cultural; } \\
\text { 9) Existência de Fundo Municipal de } \\
\text { Cultura; } \\
\text { 10) Total da despesa realizada da } \\
\text { Função Cultura ponderado pela } \\
\text { população estimada em 2006; } \\
\text { 11) Total da despesa realizada da } \\
\text { Função Cultura ponderado pelo total } \\
\text { da receita arrecadada do município; } \\
\text { 12) Existência de escola, oficina ou } \\
\text { curso regular de formação em } \\
\text { atividades típicas da cultura; }\end{array}$ & $\begin{array}{l}\text { 13) Existência de Projeto de } \\
\text { implementação de turismo cultural; } \\
\text { 14) Número de bibliotecas públicas; } \\
\text { 15) Número de museus; } \\
\text { 16) Número de teatros; } \\
\text { 17) Número de centros culturais; } \\
\text { 18) Número de estádios ou ginásios } \\
\text { poliesportivos; } \\
\text { 19) Número de cinemas; } \\
\text { 20) Existência de unidades de ensino } \\
\text { superior; } \\
\text { 21) Existência de video locadoras; } \\
\text { 22) Existência de lojas de discos, } \\
\text { CDs, fitas e DVDs; } \\
\text { 23) Existência de livrarias e grande } \\
\text { região geográfica. }\end{array}$ \\
\hline
\end{tabular}

Fonte: Machado (2012).

Como pode ser verificado no Gráfico 4 a seguir, nas regiões Sul e Sudeste está localizada a maioria dos municípios criativos, $45,13 \%$ e $30,25 \%$, respectivamente, bem como aqueles com algum potencial criativo, $29 \%$ e $34 \%$. Quase metade dos municípios não criativos está localizada na região Nordeste $(43,63 \%)$.

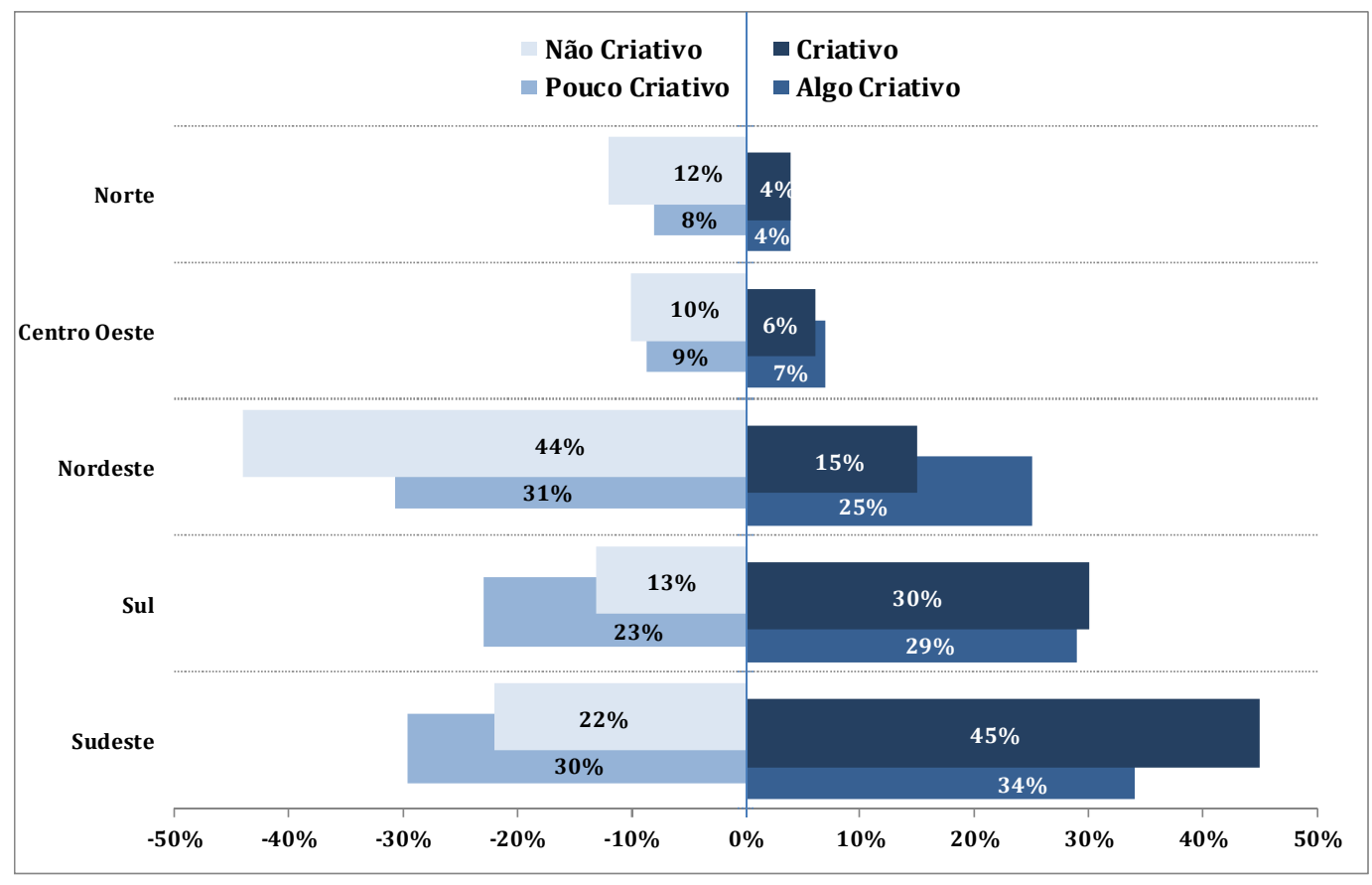

Gráfico 4 - Distribuição dos perfis por grandes regiões brasileiras, 2006

Fonte: Machado (2012).

No estudo chama atenção o fato de os municípios paranaenseses de Curitiba e Ponta Grossa - juntamente com Recife, Porto Alegre, São Paulo, Rio de Janeiro, Juiz de Fora (MG), 
Brasília, Joinville (SC) e Belo Horizonte - ocuparem posição de destaque por apresentarem as melhores características quanto às variáveis envolvidas na avaliação. Todos esses municípios, além de apresentarem nível elevado de gastos per capita com atividades criativas, contam com os equipamentos culturais em quantidade superior à média, possuem centros universitários e políticas de fomento às atividades culturais (MACHADO 2012).

Considerando conjuntamente as informações constantes dos dois gráficos acima, é interessante notar que Curitiba, mesmo possuindo as melhores condições infraestruturais para suporte a indústrias criativas, se situa na penúltima posição em relação à proporção da PEA alocada em atividades criativas. Além disso, o surgimento da cidade de Ponta Grossa dentre as de significativo pontencial criativo abre possibilidades importantes para investigações em relação a outros grandes centros urbanos paranaenses.

Independentemente desses resultados, em Curitiba começa a surgir uma série de eventos e movimentos ligados ao tema economia criativa, com tendências de expansão para outras cidades do Estado do Paraná. Um dos marcos para as discussões foi a realização do Seminário de Economia Criativa, em 2011, pelas Secretarias de Estado da Cultura do Paraná (SEEC) e Secretaria de Estado do Turismo do Paraná (SETU), com apoio do Sistema FIEP/SESI.

Desde então, dois movimentos ligados à economia criativa vem se destacando: o Fórum de Economia Criativa do Paraná, hoje Rede de Economia Criativa do Paraná, que iniciou sua estruturação em novembro de 2011 e o Movimento Curitiba Criativa, que iniciou suas atividades em maio de 2012.

\section{Conclusões}

O processo de transformação das atividades tradicionais em direção àquelas pautadas na aplicação intensiva de conhecimento apresentou tendências que se fazem visíveis em trajetória desenvolvida ao longo do último século, com intensificação no final e com impactos especialmente nas áreas urbanas. A noção de capital social ganhou relevância especialmente quanto aos níveis de aplicação de conhecimentos pela crescente classe chamada criativa. Como exemplificação do impacto de tais alterações na composição da força de trabalho na economia, os dados demonstram mudanças significativas ocorridas em diferentes países.

No campo de práticas, principalmente na formulação e implementação de políticas públicas, ainda não há referencial único e de utilização simplificada para obtenção de convergência de esforços de políticos, gestores, lideranças da sociedade civil organizada e empreendedores culturais. Situação similar ocorre também no contexto de estudos acadêmicos. Embora significativos avanços já tenham ocorrido, grandes desafios para o desenvolvimento de modelos operacionais se encontram na determinação de fronteiras entre arte, cultura e indústria para a inserção de tecnologias e colocação de produtos em contextos de negócios.

Resultados práticos provenientes da economia criativa são economicamente representativos no Brasil e apresentam tendências promissoras de ampliação. Aliado a isso, o nível das discussões sobre a temática no país também expressa elevado nível de interesse tanto da sociedade quanto de acadêmicos. Essas condições, ao formarem contexto favorável, abrem perspectivas futuras de desenvolvimento a partir de novas bases e de mobilização de novos capitais. Nesse sentido, talvez seja o caso de começar a se repensar o próprio escopo do que se considera economia criativa. A amplitude do conceito permite, pois, a instituição de políticas públicas em âmbito multissetorial e com abrangência desde serviços e produtos de 
origem artesanal até aqueles provenientes de segmentos tecnologicamente avançados. Em relação a estes últimos, pelo que se expressa no discurso oficial do governo federal, parece ainda não haver espaços suficientes para que se insiram na política de economia criativa.

A política de fomento da economia criativa de Curitiba, a exemplo do que ocorre em nível nacional, é ainda incipiente, guardadas as devidas proporções. Os esforços se encontram em perspectiva de movimentos que, por não deterem capacidade de governança suficiente para institucionalizar programas de desenvolvimento com objetivos de longo prazo, ainda são fortemente dependentes de iniciativas e da força de articulação da sociedade civil.

Em termos de perspectiva de desenvolvimento local e regional, as vocações existentes em todo estado do Paraná vão desde atrair eventos permanentes no litoral até potencializar eventos tradicionais com novas interações criativas em cidades do interior, o que abre importantes espaços para o fortalecimento de atividades de classes criativas. A mobilização de competências locais e regionais, com base em recursos imateriais, pode vir a contribuir, se devidamente articulada e fomentada por órgãos oficiais, com as novas riquezas a para grande número de municípios.

\section{REFERÊNCIAS}

AtKinson, R.; EAsthope, H. The Consequences of the Creative Class: The Pursuit of Creativity Strategies in Australia's Cities. International Journal of Urban and Regional Research, v. 33, n. 1, p. 64-79, 2009.

Australia. Creative nation: Commonwealth cultural policy. Canberra: Department of Communications and the Arts, 1994. p. 102.

. Creative Industries: a strategy for $21^{\text {st }}$ Century Australia. Canberra: Department of Regional Australia, Local Government, Arts and Sport, 2011. p. 23.

Botelho, I. Criatividade em pauta: alguns elementos para reflexão. In: Plano da Secretaria da Economia Criativa: políticas, diretrizes e ações, 2011-2014. Ministério Da Cultura (Org.). Brasília: Ministério da Cultura, 2011. p. 86-92.

BRASIL. Plano da Secretaria da Economia Criativa: políticas, diretrizes e ações, 2011-2014. Brasília: Ministério da Cultura, 2011. p. 154.

CAIAdO, A. S. C. (Org). Economia criativa: economia criativa na cidade de São Paulo diagnóstico e potencialidade. São Paulo: Fundap, 2011. 160 p.

CIEDES - Centro de Investigaciones Estratégicas y de Desarrollo Económico y Social de Málaga. Cultura y desarrollo: Impacto socioeconómico de Málaga 2016. Málaga: 2010. 70 p.

CostA, A. D.; SouZA-SANTOS, E. R. D. Economia criativa: novas oportunidades baseadas no capital intelectual. Revista Economia \& Tecnologia, v. 7, n. 2, p. 1-8, 2012.

FIRJAN - Federação das Indústrias do Estado do Rio de Janeiro. A cadeia da indústria criativa no Brasil. Rio de Janeiro: Firjan, 2008. 32 p.

FlORIDA, R. The Rise of the Creative Class: and how it's transforming work, leisure, community and everyday life. New York: Basic Books, 2002. 404 p.

HoYman, M.; FARIC, C. It takes a village: A test of the creative class, social capital, and 
human capital theories. Urban Affairs Review, v. 44, n. 3, p. 311-333, 2009.

LEITÃo, C. Criatividade e diversidade cultural brasileira como recursos para um novo desenvolvimento. In: Plano da Secretaria da Economia Criativa: políticas, diretrizes e ações, 2011-2014. Ministério da Cultura (Org.). Brasília: Ministério da Cultura, 2011. p. 1216.

Machado, A. F. Cidades Criativas. Belo Horizonte: Universidade Federal de Minas Gerais, 2012. Disponível em:

<http://web.cedeplar.ufmg.br/cedeplar/site/pesquisas/pis/Estudo\%2044.pdf>. Acesso em: 17 jan. 2014.

MigueZ, P. Economia criativa: uma discussão preliminar. In: Teorias \& políticas da cultura: visões multidisciplinares. Gisele Marchiori Nussbaumer (Org.). Salvador: EDUFBA, 2007. p. 95-113.

Newbigin, J. The creative economy: an introductory guide. London: British Council, 2010. $78 \mathrm{p}$.

PECK, J. Struggling with the Creative Class. International Journal of Urban and Regional Research, v. 29, n. 4, p. 740-770, 2005.

RUUTU, K.; PANFILO, A.; KARHUNEN, P. Cultural industries in russia: northern dimension partnership on culture. Copenhagen: TemaNord, 2009. 68 p.

SANTOS, J. F. F. As cidades criativas como modelo dinamizador do destino turístico. 2012. 135 f. Dissertação. Escola Superior de Gestão de Tomar, Instituto Politécnico de Tomar, Tomar, Portugal, 2012.

ScotT, A. J. ¿Capitalismo y urbanización en una nueva clave? La dimensión cognitivocultural. Tabula Rasa. Bogotá, Colômbia, n. 6, p. 195-217, jan./jun. 2007.

SeladA, C.; CunhA, I. V. D. Creative-based strategies in small and medium-sized cities: key dimensions of analysis. Questiones Geographicae, v. 31, n. 4, p. 43-51, 2012.

UNCTAD - United Nations Conference on Trade and Development. Creative Economy: the challenge of assessing the creative economy - towards informed policy-making. Geneva: United Nations, 2008. 331 p. $392 \mathrm{p}$

Creative Economy: a feasible development option. Geneva: United Nations, 2010.

Fortalecendo as industrias criativas para o desenvolvimento. Geneva: United Nations, 2011. 76 p.

Creative Economy Programme Geneva: United Nations Conference on Trade and Development, $2013 . \quad$ Disponível em: $<$ http://unctad.org/en/Pages/DITC/CreativeEconomy/Creative-Economy-Programme.aspx>. Acesso em: 23 jun. 2013.

UnESCO - United Nations Educational, Scientific and Cultural Organization. The Creative Cities Network. Paris: 2013. 